\title{
RANCANG BANGUN SISTEM PEMANTAUAN GETARAN KERETA REL LISTRIK COMMUTER LINE SECARA ONLINE
}

\author{
Erna Kusuma Wati ${ }^{\star}$, Fraska Anangga \\ Teknik Fisika, Universitas Nasional \\ ernakusuma.w@gmail.com
}

\begin{abstract}
Abstrak. Pemukiman padat yang berada disekitar jalur kereta api perlu adanya alat pemantau getaran yang dapat memantau percepatan getaran. Tingkat resiko terhadap paparan getaran dapat menyebabkan gangguan kesehatan. Diperlukan alat pengukur getaran yang dapat mengetahui nilai percepatan getaran $K R L$ yang melintas, agar dapaat dijadikan referensi dalam mendirikan pemukiman. Penelitian ini telah berhasil merancang sistem pengukuran getaran KRL dan dapat menampilkan secara online, dengan menggunakan sensor accelerometer ADXL345, board Arduino Uno, dan Modul ESP8266. Pada penelitian ini, dilakukan pengambilan data di pinggir rel kereta api dengan jarak masing-masing sensor sebesar 4 meter. Sensor akan mendeteksi perubahan getaran di sekitar rel kereta api saat dilalui oleh kereta api yang sedang melintas. Selanjutnya data tersebut dikirimkan ke webserver menggunakan modul ESP8266. Dampak getaran yang di hasilkan oleh kereta api yang melintas dapat mengakibatkan gangguan kesehatan dalam jangka panjang dengan jarak \pm 5 meter dari rel kereta api. Getaran yang di hasilkan dengan nilai terbesar pada jarak 1 meter dari rel kereta api sebesar $0,983507 \mathrm{~m} / \mathrm{s}^{2}$, pada jarak 5 meter dari rel kereta api sebesar $0,491333 \mathrm{~m} / \mathrm{s}^{2}$, Pada jarak 9 meter dari rel kereta api sebesar $0,12 \mathrm{~m} / \mathrm{s}^{2}$, dan pada jarak 13 meter dari rel kereta api sebesar 0,026 m/s.
\end{abstract}

Kata kunci: resiko paparan getaran, loT, kereta rel listrik

\begin{abstract}
Dense settlements around the railroad track need a vibration monitoring device that can monitor the acceleration of vibrations. The level of risk of exposure to waves can cause health problems. A vibration measuring device can determine the acceleration value of a passing KRL vibration so that it can be as a reference in establishing settlements. This research has succeeded in designing a KRL vibration measurement system and can display it online, using the ADXL345 accelerometer sensor, Arduino Uno board, and ESP8266 Module. The sensor will detect changes in vibration around the railroad tracks when passed by a passing train. Furthermore, the data is sent to the webserver using the ESP8266 Module. The impact of vibrations generated by the moving train can cause health problems in the long run with a distance of \pm 5 meters from the railroad tracks. The wave to show with the most substantial value at a distance of 1 meter from the railroad was $0.983507 \mathrm{~m} / \mathrm{s}^{2}$, at a distance of 5 meters from the railroad was $0.491333 \mathrm{~m} / \mathrm{s}^{2}$, At a distance of 9 meters from the railroad was $0,12 \mathrm{~m} / \mathrm{s}^{2}$, and at a distance of 13 meters from the railroad tracks of 0.026 $\mathrm{m} / \mathrm{s}$.
\end{abstract}

Keywords: risk of vibration exposure, IoT, commuter line train

\section{LATAR BELAKANG}

Pemukiman padat di sekitar jalur kereta api sudah bukan menjadi hal yang aneh lagi bagi Indonesia khususnya DKI Jakarta. Ha ini merupakan masalah sosial yang terjadi di masyarakatat indonesia. Hingga saat ini permasalahan tersebut belum mampu diselesaiakan oleh pemerintah [1]. Resiko yang harus dihadapi oleh penduduk yang tinggal disekitarnya pun cukup banyak, selain bahaya ancaman keselamatan yang dapat terjadi dikarenakan banyaknya aktifitas masyarakat disekitar jalur kereta, resiko kesehatan juga mengancam mereka [2]. Kepadatan penduduk dan kebisingan dari kereta api juga merupakan faktor pemicu terjadinya resiko gangguan kesehatan terhadap penduduknya. 
$\mathrm{KRL}$ commuter Line merupakan transportasi umum yang menjadi andalan masyarakat perkotaan untuk mobilitas yang aman, nyaman dan bebas dari kemacetan. Oleh karena nya jam operasional KRL kian padat setiap harinya [3]. Melihat jam operasionalnya yang hampir setiap sepuluh meni sekali kereta bahkan saat bersamaan bisa dua kereta yang melintas, maka penduduk yang tinggal sangat dekat dari pinggir rel sangat beresiko sekali, dari segi keselematan dan kesehatan.

Penelitian ini akan dilakukan perncangan sistem untuk melakukan pengukuran terhadap getaran $\mathrm{KRL}$ yang melintas, dengan menggunakan sensor getar. Pengukuran dilakukan dengan melakukan variasi jarak, semakin menjauhi dari rel (arah horizontal) dengan menggunakan 4 buah alat pengukur. Selanjutnya hasil pengukuran akan dikirmkan secara online ke web server secara real time.

Perancangan alat pada sistem pemantau getaran $\mathrm{KRL}$ secara keseluruhan seperti pada Gambar. terdiri dari Sensor accelerometer ADXL345, Arduino Uno yang dilengkapi dengan modul wifi ESP8266.

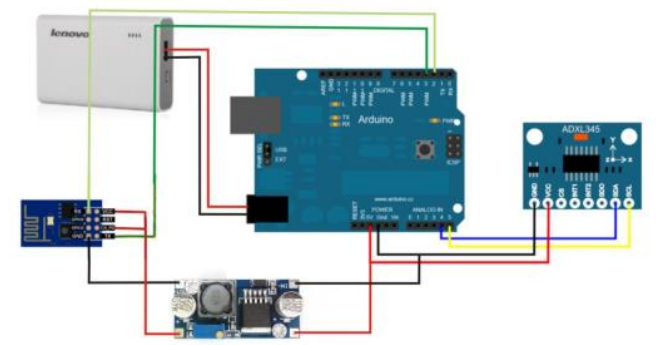

Gambar 1. Rancangan Sistem secara keseluruhan.

Perancangan modul Wifi
ESP8266 menggunakan
mikrokontroler ATMEGA328 yang
berada pada Arduino UNO.
Komunikasi modul wifi ESP8266
menggunakan pin yang tersedia pada
modul ESP8266 dengan tegangan

yang digunakan sebesar 3,3 volt. Jika nilai getaran sudah terbaca maka proses selanjutnya adalah mengirimkan data ke webserver. Untuk melakukan pengiriman data menggunakan jaringan internet dengan modul wifi ESP8266 maka di perlukan hotspot yang bisa memancarkan sinyal wifi untuk digunakan oleh modul ESP8266.

Pada penelitian ini, pengukuran dilakukan pada jarak yang berbeda dengan 4 buah sensor sekaligus. Penentuan jarak dan posisi sensor adalah sebagai berikut

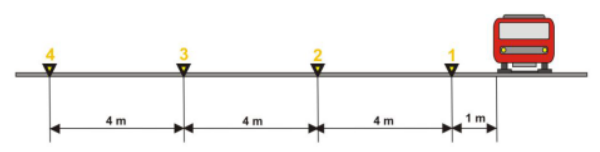

Gambar 2. Posisi sensor pada pengambilan data

Sensor 1 berada paling tepi dengan rel kereta yang berada pada jarak 1 meter, sensor 2 berada pada jarak 5 meter dari tepi rel, sensor 3 berada pada jarak 9 meter, dan sensor 4 pada jarak 13 meter.

\section{HASIL DAN ANALISIS DATA}

Penelitian ini diawali dengan
melakukan beberapa tahapan
pengujian sebelum melakukan
pengukuran secara langsung ke
lapangan.

\section{Pengujian Sensor}

Pengujian sensor dilakuan dengan memprogram sensor untuk mencari sumbu $\mathrm{z}$ yang di hasilkan oleh sensor ADXL345. Pada kondisi diam sensor akan membaca percepatan getaran sebesar $1 \mathrm{~g}(9,8$ $\mathrm{m} / \mathrm{s}^{2}$. $\quad$ Pada pengujian ini menggunakan waterpas untuk mengukur atau menentukan 
keseimbangan posisi sensor vertikal atau pun horizontal.

\section{Pengujian Terhadap Sensor 1:}

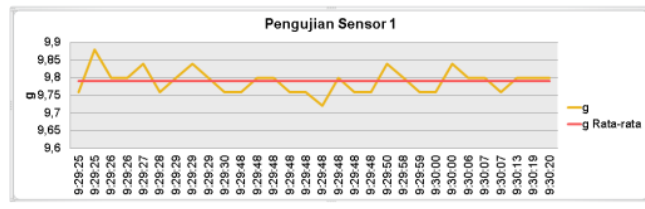

\section{Pengujian terhadap sensor 2:}

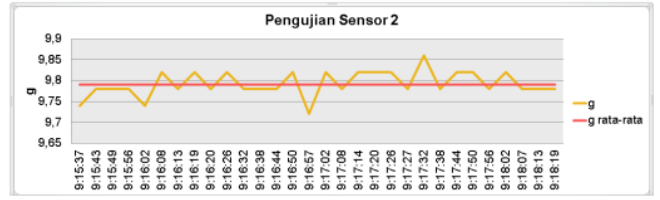

\section{Pengujian terhadap sensor 3:}

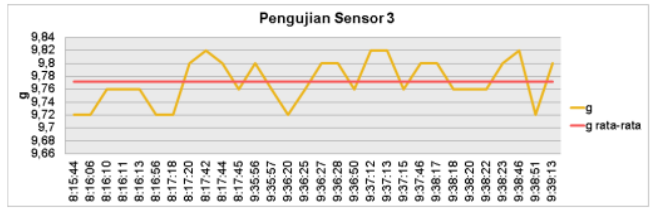

Pengujian terhadap sensor 4:

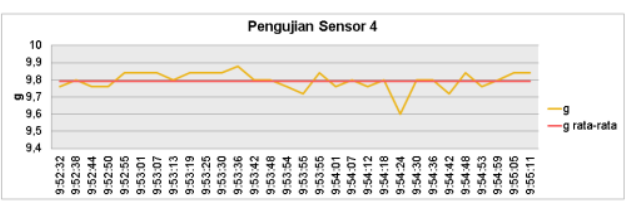

Gambar 4. Hasil Pengujian pada masingmasing sensor.

Pada pengujian masing-masing sensor dilakukan dengan mengambil 30 sampel data pada sumbu $z$. Sensor 1 rata-rata sumbu $z$ yang di dapatkan sebesar 252,77 dan ratarata gravitasi yang di dapatkan sebesar $9,79 \mathrm{~m} / \mathrm{s}^{2}$. Sensor 2 dengan rata-rata sumbu z yang di dapatkan sebesar 242,27 dan rata-rata gravitasi yang di dapatkan sebesar $9,79 \mathrm{~m} / \mathrm{s}^{2}$. Sensor 3 dengan rata-rata sumbu $z$ yang di dapatkan sebesar 259,13 dan rata-rata gravitasi yang di dapatkan sebesar $9,77 \mathrm{~m} / \mathrm{s}^{2}$. Sensor 4 dengan rata-rata sumbu $z$ yang di dapatkan sebesar 239 dan rata-rata gravitasi yang di dapatkan sebesar $9,79 \mathrm{~m} / \mathrm{s}^{2}$.
Setelah dilakukan pengujian terhadap masing sensor maka, dilakukan pengukuran terhadap getaran kereta secara langsung

\section{Pengambilan data pengukuran pada KRL yang melintas.}

Pengambilan data dilakukan dengan menghitung waktu ketika kereta api melintas sampai melewati alat pengukuran. Pada pengambilan data dilakukan pengukuran terhadap $3 \mathrm{KRL}$ yang melintas. Setiap kereta yang melintas maka ke empat alat pengukur(sensor) akan merekam getarannya.

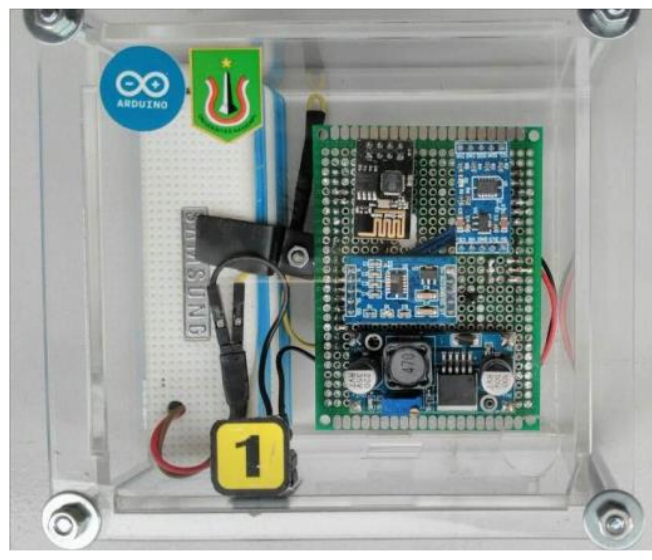

Gambar 5. Alat sistem Pengukur Getaran (tampak atas)

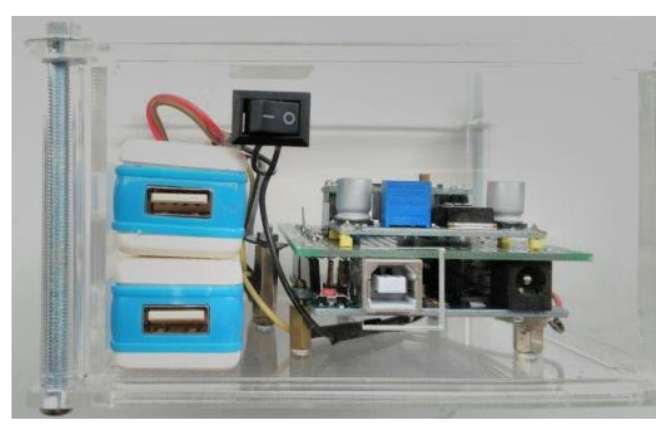

Gambar 6. Alat sistem Pengukur Getaran (tampak samping)

Adapun respon masing-masing dari sensor terhadap $K R L$ 1, 2, dan 3 yang melintas adalah sebagai berikut: 
Tabel 2. Hasil Pengukuran terhadap KRL yang melintas.

\begin{tabular}{|l|l|l|l|}
\hline Sensor & $\begin{array}{c}\text { KRL 1 } \\
\left(\mathbf{m} / \boldsymbol{s}^{2}\right)\end{array}$ & $\begin{array}{c}\text { KRL 2 } \\
\left(\mathbf{m} / \mathbf{s}^{2}\right)\end{array}$ & $\begin{array}{c}\text { KRL 3 } \\
\left(\mathbf{m} / \mathbf{s}^{2}\right)\end{array}$ \\
\hline Sensor 1 & 0,89 & 0,13 & 0,98 \\
\hline Sensor 2 & 0,33 & 0,15 & 0,49 \\
\hline Sensor 3 & 0,12 & $-0,08$ & 0,03 \\
\hline Sensor 4 & $-0,07$ & 0,05 & 0,02 \\
\hline
\end{tabular}

Ket. : Tanda negatif (-) menandakan arah getaran.

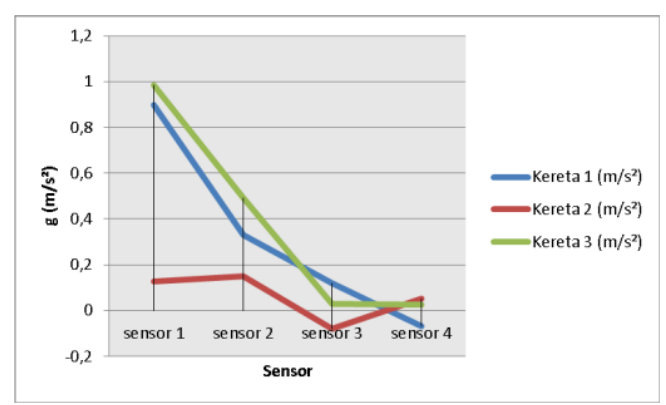

Gambar 7. Grafik Hasil Pengukuran Sensor Terhadap KRL yang melintas.

Dari hasil pengukuran, diketahui nilai percepatan pada masing-masing sensor berbeda, semakin jauh jarak sensor terhadap rel maka nilai percepatannya semakin kecil. Sensor 1 terletak 1 meter dari tepi rel menunjukkan hasil yang sangat besar dibdandingkan dengan ke tiga sensor lainnya, dan sensor ke 4 pada jarak 13 meter dari rel memiliki nilai percepatan yang lebih kecil.

Dengan melakukan variasi jarak pada masing-masing sensor maka dpaat diketahui jarak minimal untuk mendirikan suatu bangunan penduduk agar trehindar dari resiko paparan dari getaran dari KRL.

\section{Analisis Tingkat Resiko Terhadap Paparan Getaran Kereta}

Berdasarkan Tabel 1 mengenai tingkat resiko paparan getaran kereta, maka berikut hasil analisanya pada masing-masing kereta.

\section{Kereta 1}

Nilai getaran pada sensor 1 sebesar $0,89934 \mathrm{~m} / \mathrm{s}^{2}$, nilai getaran yang terbaca pada sensor 1 masuk ke dalam tingkat resiko sedang yaitu berkisar 0,45 - 0,90, pada tingkat resiko sedang dampak paparan getaran berada di zona Health Guidance Caution Zone (HGCV) yang dapat menimbulkan potensi resiko bagi kesehatan.

Nilai getaran pada sensor 2 sebesar $0,33 \mathrm{~m} / \mathrm{s}^{2}$, nilai getaran yang terbaca pada sensor 2 masuk ke dalam tingkat resiko rendah yaitu < 0,45 , pada tingkat resiko sedang dampak paparan getaran masih berada di zona Health Guidance Caution Zone (HGCV) yang dimana kasus penyakit belum pernah ditemui.

Nilai getaran pada sensor 3 sebesar $0,12 \mathrm{~m} / \mathrm{s}^{2}$, nilai getaran yang terbaca pada sensor 3 masuk ke dalam tingkat resiko rendah yaitu < 0,45 , pada tingkat resiko rendah dampak paparan getaran masih berada di zona Health Guidance Caution Zone (HGCV) yang dimana kasus penyakit belum pernah ditemui.

Nilai getaran pada sensor 4 sebesar $-0,07 \mathrm{~m} / \mathrm{s}^{2}$, nilai getaran yang terbaca pada sensor 4 masuk ke dalam tingkat resiko rendah yaitu < 0,45 , pada tingkat resiko rendah dampak paparan getaran masih berada di zona Health Guidance Caution Zone (HGCV) yang dimana kasus penyakit belum pernah ditemui.

\section{Kereta 2}

Nilai getaran pada sensor 1 sebesar $0,127574 \mathrm{~m} / \mathrm{s}^{2}$, nilai getaran yang terbaca pada sensor 1 masuk ke dalam tingkat resiko rendah yaitu < 0,45 , pada tingkat resiko rendah dampak paparan getaran masih berada di zona Health Guidance 
Caution Zone (HGCV) yang dimana kasus penyakit belum pernah ditemui. Nilai getaran pada sensor 2 sebesar $0,15 \mathrm{~m} / \mathrm{s}^{2}$, nilai getaran yang terbaca pada sensor 2 masuk ke dalam tingkat resiko rendah yaitu $<0,45$, pada tingkat resiko rendah dampak paparan getaran masihberada di zona Health Guidance Caution Zone (HGCV) yang dapat menimbulkan potensi resiko bagi kesehatan.

Nilai getaran pada sensor 3 sebesar $-0,08 \mathrm{~m} / \mathrm{s}^{2}$, nilai getaran yang terbaca pada sensor 3 masuk ke dalam tingkat resiko rendah yaitu < 0,45, pada tingkat resiko sedang dampak paparan getaran masih berada di zona Health Guidance Caution Zone (HGCV) yang dimana kasus penyakit belum pernah ditemui.

Nilai getaran pada sensor 4 sebesar $0,05 \mathrm{~m} / \mathrm{s}^{2}$, nilai getaran yang terbaca pada sensor 4 masuk ke dalam tingkat resiko rendah yaitu < 0,45 , pada tingkat resiko sedang dampak paparan getaran masih berada di zona Health Guidance Caution Zone (HGCV) yang dimana kasus penyakit belum pernah ditemui

\section{Kereta 3}

Nilai getaran pada sensor 1 sebesar $0,983507 \mathrm{~m} / \mathrm{s}^{2}$, nilai getaran yang terbaca pada sensor 1 masuk ke dalam tingkat resiko tinggi yaitu > 0,90 , pada tingkat resiko tinggi dampak paparan getaran berada di atas zona Health Guidance Caution Zone (HGCV) yang dimana resiko kesehatan sering terjadi pada tingkat ini.

Nilai getaran pada sensor 2 sebesar $0,491333 \mathrm{~m} / \mathrm{s}^{2}$, nilai getaran yang terbaca pada sensor 2 masuk ke dalam tingkat resiko sedang yaitu $0,45-0,90$, pada tingkat resiko sedang dampak paparan getaran masih berada di zona Health Guidance Caution Zone (HGCV) yang dapat menimbulkan potensi resiko bagi kesehatan.
Nilai getaran pada sensor 3 sebesar $-0,08 \mathrm{~m} / \mathrm{s}^{2}$, nilai getaran yang terbaca pada sensor 3 masuk ke dalam tingkat resiko rendah yaitu < 0,45 , pada tingkat resiko sedang dampak paparan getaran masih berada di zona Health Guidance Caution Zone (HGCV) yang dimana kasus penyakit belum pernah ditemui.

Nilai getaran pada sensor 4 sebesar $0,05 \mathrm{~m} / \mathrm{s}^{2}$, nilai getaran yang terbaca pada sensor 4 masuk ke dalam tingkat resiko rendah yaitu < 0,45 , pada tingkat resiko sedang dampak paparan getaran masih berada di zona Health Guidance Caution Zone (HGCV) yang dimana kasus penyakit belum pernah ditemui.

Pengukuran yang dilakukan ini juga dapat terpantau secara real time di website. Untuk mengakses perlu melakukan login denan username dan password. adapun hasilnya adalah sebagai berikut
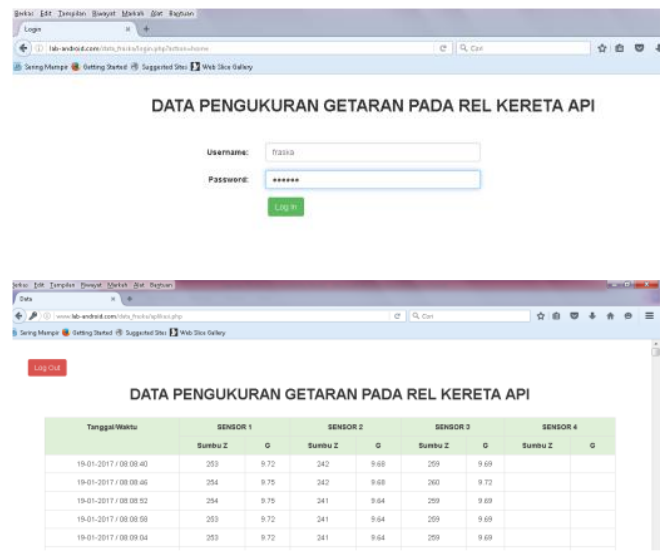

Gambar 8. Tampilan Pada Website hasil pengukuran.

\section{KESIMPULAN}

Pada penelitian telah dirancang bangun sistem monitoring pengukur getaran rel kereta api (Hard Track) dengan modul ESP8266 sebanyak 4 buah alat pengukuran dan berhasil menampilkan data hasil monitoring getaran dengan webserver. 
Dampak getaran yang di hasilkan oleh kereta api yang melintas dapat mengakibatkan gangguan kesehatan dalam jangka panjang dengan jarak \pm 5 meter dari rel kereta api, getaran yang di hasilkan dengan nilai terbesar pada jarak 1 meter dari rel kereta api sebesar $0,983507 \mathrm{~m} / \mathrm{s}^{2}$, pada jarak 5 meter dari rel kereta api sebesar $0,491333 \mathrm{~m} / \mathrm{s}^{2}$, Pada jarak 9 meter dari rel kereta api sebesar $0,12 \mathrm{~m} / \mathrm{s}^{2}$, dan pada jarak 13 meter dari rel kereta api sebesar $0,026 \mathrm{~m} / \mathrm{s}^{2}$.

di akses menggunakan laptop dengan jaringan internet

Pengujian pada keempat sensor berdasarkan tingkat resiko terhadap paparan getaran bagi kesehatan masuk ke dalam kategori rendah yaitu $<0,45 \mathrm{~m} / \mathrm{s}^{2}$.

\section{DAFTAR PUSTAKA}

1. Agus Margiantono dan Evi Setiawati. Prediksi Peningkatan Getaran Di Zona Jalur Kereta Api Sebagai Dampak Adanya Double Track (Yang Akan Dibangun) Untuk Pembangunan Berkelanjutan. ISSN 1410-9840, Volume 11 No 2, Desember 2009.

2. Bridge Assesment Using ForcedVibration Testing, Journal of Structural Engineering 121:161173. 1995.

3. Benny Kresno Sunarko. Analisa Getaran Pada Mesin Sepeda Motor Berbasis Labview. Universitas Indonesia, FMIPA, Program Magister Fisika Kekhususan Fisika Instrumentasi. 2010.
4. Fajar Sugih Rizqillah, Rendy Munadi, Indra Chandra. Perancangan Dan Implementasi Wireless Sensor Network (WSN) Untuk Monitoring Getaran Rel Kereta Api Berbasis Accelerometer 3 Sumbu Menggunakan Protokol ZIGBEE. Teknik Telekomunikasi, Fakultas Teknik Elektro, Universitas Telkom. IEEE 802.15.4. 2013

5. Harry Yuliansyah. Uji Kinerja Pengiriman Data Secara Wireless Menggunakan Modul ESP8266 Berbasis Rest Architecture. Lampung Selatan : Teknik Elektro, Institut Teknologi Sumatera. 2016

6. Keputusan Menteri Negara Lingkungan Hidup. Kep. No. 49/MENLH/11/1996 tentang Baku Tingkat Getaran. Jakarta. 1996

7. Mark Serridgedan Torben $\mathrm{R}$. Licht, Piezoelectric Accelerometer and Vibration Preamplifier Handbook, Larsen \& Son A/S. Denmark. 1987.

8. Massimo Banzi, Getting Started with Arduino. U.S.A. 2011

9. MMA7361L Datasheet, Freescale Semiconductor.

10. Nugroho, Bunafit, PHP dan My SQL dengan Editor Dreamweaver MX, Penerbit Andi. Yogyakarta. 2004.

11. R. P. Areny dan J. G. Webster, Sensor and Signal Conditioning, Canada: John Wiley \& Sons, Inc, 1991.

12. Taferner, M., dan Bonek, E., Wireless Intenet Access over GSM and UMTS, Springer, Berlin, 2002 